\title{
Correction to: Targeted metabolomic analysis identifies increased serum levels of GABA and branched chain amino acids in canine diabetes
}

\author{
Allison L. O'Kell ${ }^{1}$ (1) . Clive Wasserfall ${ }^{2} \cdot$ Joy Guingab-Cagmat ${ }^{3} \cdot$ Bobbie-Jo M. Webb-Robertson $^{2,4} \cdot$ Mark A. Atkinson $^{2}$. \\ Timothy J. Garrett ${ }^{2}$
}

Received: 13 December 2021 / Accepted: 15 December 2021 / Published online: 19 December 2021

(c) The Author(s), under exclusive licence to Springer Science+Business Media, LLC, part of Springer Nature 2021

\section{Correction to: Metabolomics (2021) 17:100 \\ https://doi.org/10.1007/s11306-021-01850-y}

Unfortunately, in the original publication of the article, the fourth author surname was inadvertently misspelled as "Webb-Roberston" instead of "Webb-Robertson". This has now been corrected with this erratum.

Publisher's Note Springer Nature remains neutral with regard to jurisdictional claims in published maps and institutional affiliations.

The original article can be found online at https://doi.org/10.1007/ s11306-021-01850-y.

Allison L. O'Kell

aokell@ufl.edu

1 Department of Small Animal Clinical Sciences, College of Veterinary Medicine, The University of Florida, 2015 SW 16th Ave, Box 100116, Gainesville, FL 32608, USA

2 Department of Pathology, Immunology, and Laboratory Medicine, The University of Florida, Gainesville, FL, USA

3 Southeast Center for Integrated Metabolomics, Clinical and Translational Science Institute, The University of Florida, Gainesville, FL, USA

4 Biological Sciences Division, Pacific Northwest National Laboratory, Richland, WA, USA 